DOI 10.37882/2223-2982.2020.04-2.12

\title{
МАНИПУЛЯТИВНАЯ ТАКТИКА РАЗМЕЖЕВАНИЯ В ПОЛИТИЧЕСКОМ ИНТЕРНЕТ-ДИСКУРСЕ (НА ОСНОВЕ МИКРОБЛОГА ТWITTЕR)
}

\section{MANIPULATIVE TACTICS OF DISTRIBUTION IN POLITICAL INTERNET DISCOURSE (BASED ON TWITTER) \\ A. Glushchenko}

Summary: This study examines the political Internet discourse within the framework of the social platform Twitter, in particular, the manipulative tactics of disengagement, which is part of the modern direction of Twitter diplomacy. This subspecies of digital diplomacy has a special place in the political activities of public and state representatives of most countries.

Keywords: political Internet discourse, strategies and tactics of manipulation, theatricality strategy, demarcation tactics, social networks, Twitter-diplomacy, linguistic policy.

\author{
Глущенко Александра Николаевна \\ Соискатель, Кубанский государственный университет \\ (Краснодар) \\ aleksandraglushchenko@gmail.com
}

Аннотация: В данном исследовании рассматривается политический Интернет-дискурс в рамках социальной платформы Twitter, в частности, манипулятивная тактика размежевания, которая является частью современного направления Twitter-дипломатии. Данный подвид цифровой дипломатии занимает особое место в политической деятельности общественных и государственных представителей большинства стран.

Ключевые слова: политический Интернет-дискурс, стратегии и тактики манипулирования, стратегия театральности, тактика размежевания, социальные сети, Twitter-дипломатия, лингвистическая политика.

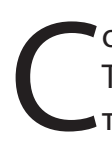

оздание и активация в 2006 году социальной сети Twitter ознаменовало появление нового вида интерактивного общения во Всемирной Паутине. Название данной социальной платформы происходит от английского слов «tweet», т.е. «щебетать, болтать». Коммуникация в Twitter обладает отличительными особенностями, обусловленными спецификой самой социальной сети, а именно ограниченное количество символов в одном микросообщении - 280 (включая буквы, пробелы и знаки препинания). Интернет-общение внутри платформы давно вышло за пределы повседневного дискурса, участниками которого являются только простые пользователи. Так, например, отечественный лингвист Т.В. Харламова отмечает, что «социальные сети не только влияют на развитие общества, но и предлагают новые способы взаимодействия политической власти и общества» [1, с. 396]. Более того, современные лингвисты, политологи и даже сами политические и государственные деятели говорят о появлении совершенно нового подвида цифровой дипломатии - Twitter-дипломатии. Альфредо А. Торреальба определяет, что «данный вид политического общения «относится к использованию Twitter со стороны глав государств, руководителей межправительственных организаций и дипломатов, для сближения позиций по международным вопросам» [2, с. 157]. Согласно Т. Зоновой, «объяснение феномена Twitterдипломатии связано с увеличивающейся необходимостью политиков иметь больше контактов с людьми» [3].

В основе любого вида политического дискурса лежит одна цель - манипулирование сознанием населения, а также влияние на внутреннюю и внешнюю политическую ситуацию. В рамках социальной сети Twitter политики также преследуют цель привлечения большого количества потенциальных избирателей и сторонников, что предполагает использование ряда коммуникативных стратегий и тактик манипулирования. О.Л. Михалёва в своем исследовании выделяет три вида стратегий - на понижение, на повышение и стратегия театральности, каждая из которых также содержит в себе несколько подвидов - манипулятивных тактик воздействия. [4, с. 57]. В данной статье мы рассматриваем стратегию театральности, которая включает в себя девять тактик:

- тактика побуждения;

- тактика размежевания;

- тактика обещания;

- тактика кооперации;

- тактика информирования;

- тактика иронизирования;

- тактика провокации;

- тактика прогнозирования;

- тактика предостережения.

В исследовании мы проводим анализ примеров из социальной сети Twitter тактики размежевания. Данная тактика воздействия основывается на принципе «свой» - «чужой». Условия ее реализации определяются разделением участников политического коммуникативного процесса на две группы. Первая группа - это условные враги, действия и поступки которых автор пытается 
представить в худшем свете или на контрасте с чужими действиями. В то время как вторая группа участников коммуникации - это положительные герои (иногда в их число входит и сам автор), чьи политические действия выступают на благо общества. Данный вид манипулятивной тактики отсылается к самой стратегии театральности, которая обладает сходствами с реальной постановкой. На театральной сцене, как в драме, так и в комедии, всегда существуют герои и злодеи (непосредственные участники коммуникативного процесса). В то время как пользователи социальной сети (простые граждане) являются зрителями данной постановки. Все тактики стратегии театральности зачастую насыщены эмоционально-экспрессивными компонентами, позволяющими не только передать посыл автора, но и привлечь внимание читателя. Итак, рассмотрим несколько примеров из социальной сети Twitter. Например,

'I was criticized by the Democrats when I closed the Country down to China many weeks ahead of what almost everyone recommended. Saved many lives. Dems we working the Impeachment Hoax. They didn't have a clue! Now they are fear mongering. Be calm \& vigilant!' (твит от 2 марта 2020 года) Демократы критиковали меня за то, что я закрыл страну для Китая за много недель до того, как все стали рекомендовать это. И спас много жизней. Демократы работали над поддельным импичментом. У них не было и идеи! Теперь же они борются со страхом. Будьте спокойны и бдительны! (перевод автора)

Данный твит от президента Соединённых Штатов Америки Дональда Трампа из социальной сети Twitter является ярким примером манипулятивной тактики размежевания. Автор микросообщения проводит четкую параллель между «своими (I) и «чужими» (the Democrats). Проводя подобное сравнение Трамп приводит в пример свои положительные поступки - saved many lives, а в противовес им отрицательные действия оппонента - I was criticized by the Democrats. Более того, в своем микропосте автор говорит о бесполезных, с его точки зрения, вопросах, которыми занимались «чужие» - Dems were working the Impeachment Ноах. Это отсылает читателя к существующему разногласию между президентом Америки и правящей партией Демократов, которые активно пытаются на протяжении всего срока призвать Трампа к импичменту, а также приписывают ему тайный сговор с Россией и бесконтрольность его политических решений. Дональд Трамп - это уникальная персона для Twitterдипломатии, поскольку многие лингвисты и политолог говорят о нём, как о родоначальнике данного направления политического дискурса. В своих твитах президент Америки часто очень эмоционален и экспрессивен, иногда также он прибегает к не нормативной или просторечной лексике. Так, например, и в данном микропосте он прибегает к восклицательным знакам, которые помогают передать читателям его эмоциональное состояние.
«Готовятся провокации. Меня не допускают к проверке собственных же подписных листов. Отстоять свое право на честные выборы мы можем, показав, что мы вместе и нас много! 14 июля в 14 ч встреча с кандидатами в Новопушкинском сквере!» (твит от 12 июля 2019 года)

Данный микропост принадлежит представителю оппозиционного движения Любови Соболь. Твит был опубликован на фоне предвыборной кампании в Московскую Государственную Думу в сентябре 2019 года, в участии в которой кандидату Соболь было отказано по причине превышения количества испорченных подписей. На фоне этого конфликта в социальной сети Twitter было опубликовано большое количество микропостов как в поддержку, так и против данного кандидата. В представленном микропосте автор прибегает к тактике размежевания, в которой она и её сторонники - это «свои» (мы вместе и нас много), а те, кто не допускают её к проверке, являются «чужими» (готовятся провокации). Любовь Соболь не обозначает имён и фамилий, а также не дает каких-либо местоимений для обозначения оппонента. Такой принцип предполагает, что читатели осведомлены о враге и не нуждаются в объяснении. Поступки «своих» резко положительные - отстоять своё право на честные выборы, которые в значительной степени обладают поддержкой сторонников и приверженцев схожих политических взглядов. Как и автор предыдущего твита, президент США Дональд Трамп, Соболь в своём микросообщении эмоциональна, что определяется использованием восклицательного знака в конце повествования. На данном примере также можно пронаблюдать особенности политического Интернет-дискурса в рамках конкретной социальной платформы - автор, согласно символьным ограничениям в знаках, сокращает слово «часов» до буквы «ч», а также не использует полное часовое обозначение - «14» вместо «14:00». Данные сокращения обусловлены ограниченным количеством символов в Twitter.

'6 tears ago, Russia occupied Crimea. We realized that we live in a world where memoranda are worthless, the systems of international laws \& security are vulnerable. We are doing everything to stop the war in the Donbas. Crimea isn't removed from the agenda \& isn't a price for peace' (от 26 февраля 2020 года) - 6 лет назад Россия оккупировала Крым. Мы поняли, что живем в мире, где меморандумы бесполезны, а системы международного права и безопасности уязвимы. Мы делаем все, чтобы остановить войну на Донбассе. Крым не снят с повестки дня и не является разменной монетой нашего перемирия. (перевод автора)

Автором данного твит, как примера реализации манипулятивной тактики размежевания, является президент Украины Володимир Зеленський. Во-первых, стоит обратить внимание на то, что он публикует пост на ан- 
глийском языке, а не на родном украинском для того, чтобы данный твит получил распространение в мировом сообществе. По этой же причине автор не написал пост на русском языке, который был бы понятен его оппоненту. Во-вторых, Зеленський, вопреки негласным правилам классической формы дипломатии, прибегает к сокращенным формам - isn't, а также '\&' вместо слова 'and', что обусловлено спецификой символьного ограничения в данной социальной сети Автор, в отличие от предыдущего твита Любови Соболь, обозначает своего врага - Russia. Президент Украины в своем микропосте подбирает определенный набор лексических единиц, которые позволяют ему задать отрицательный тон при описании политических действии оппонента в рамках лексической группа «война» - occupied, memoranda are worthless, war, a price for peace. В самом твите появляются несколько топонимов - Crimea, the Donbas, которые являются центром политических интересов обеих стран.
Несмотря на то, что автор использует достаточно громкие политические выражения (a price for peace, laws \& security are vulnerable), он не переходит к оскорблению оппонента, а также не использует просторечную и грубую лексику.

На основе представленных примеров из социальной сети Twitter, можно сделать вывод, что манипулятивная тактика размежевания применяется политиками многих стран. В данной статье мы рассмотрели представителей трёх стран - России, Украины и США, каждый из представителей которых публиковал микросообщения в данной тактике. Основной принцип универсален - наличие разделения на «своих» и «чужих». Однако каждый из политиков помимо реализации твитов в рамках политического Интернет-дискурса, также следует своим личным принципам коммуникативного дискурса.

\section{ЛИТЕРАТУРА}

1. Харламова Т.В. Социальные сети как инструмент современной политической власти (на материале микроблога Д. Трампа в Твиттере) // Изв. Сарат. Ун-та. Нов. сер. Сер. Филология. Журналистика. 2018. - Т.18, вып.4 - С. 394-399

2. Альфредо А. Торреальба. Твитпломатия: влияние социальной сети Twitter на дипломатию // Вестник РУдН, серия Международные отношения, 2015. том 15, №3 - 241 c.

3. Зонова Т. Публичная дипломатия и его деятели [электронный ресурс] http://russianconcil.ru/en/inner/?id_4=718\#top (дата 0бращения: 10.02.2020).

4. Михалёва 0.Л. Политический дискурс. Специфика манипулятивного воздействия. М.: Либроком, 2009. 256 с.

\footnotetext{
(с Глущенко Александра Николаевна (aleksandraglushchenko@gmail.com).

Журнал «Современная наука: актуальные проблемы теории и практики»
}

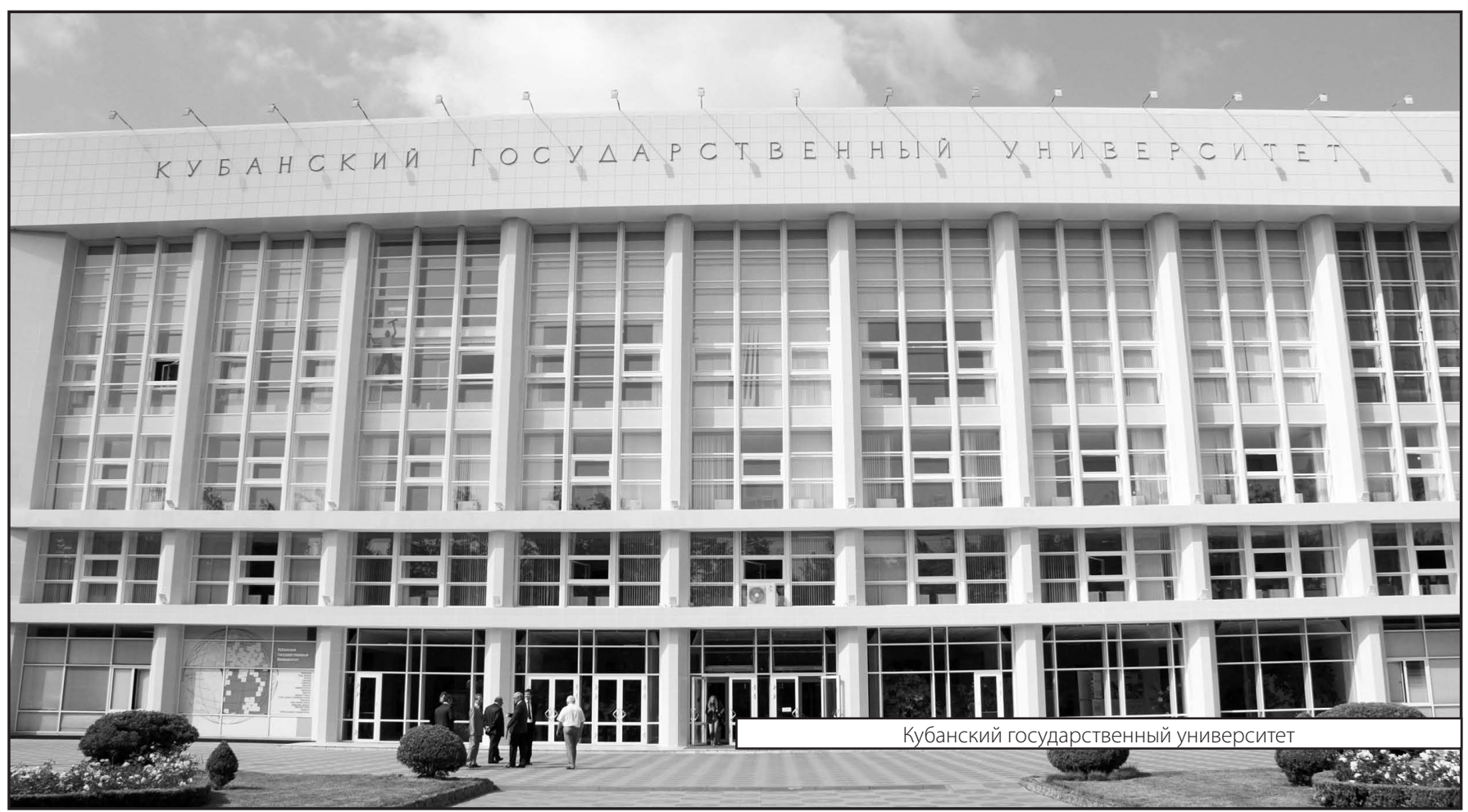

